\title{
Molecular surveillance of drug-resistance associated mutations of Plasmodium falciparum in south-west Tanzania
} Mirjam Schönfeld ${ }^{1}$, Isabel Barreto Miranda ${ }^{1}$, Mirjam Schunk1, Ibrahim Maduhu², Leonard Maboko³, Michael Hoelscher ${ }^{1,3}$, Nicole BerensRiha ${ }^{1}$, Andrew Kitua ${ }^{4}$ and Thomas Löscher*1

Address: ${ }^{1}$ Department of Infectious Diseases and Tropical Medicine, Ludwig-Maximilians- University (LMU), Munich, Germany, ${ }^{2}$ Department of Paediatrics and Child Health, Mbeya Referral Hospital, Tanzania, ${ }^{3}$ Mbeya Medical Research Programme (MMRP), Mbeya, Tanzania and ${ }^{4}$ National Institute for Medical Research (NIMR), Dar es Salaam, Tanzania

Email: Mirjam Schönfeld - mimischoen@web.de; Isabel Barreto Miranda - barretomiranda@lrz.uni-muenchen.de; Mirjam Schunk - mschunk@mmrp.org; Ibrahim Maduhu - nyasilu55@yahoo.com; Leonard Maboko - lmaboko@mmrp.org; Michael Hoelscher - hoelscher@lrz.uni-muenchen.de; Nicole Berens-Riha - berens@lrz.uni-muenchen.de; Andrew Kitua - akitua@nimr.or.tz; Thomas Löscher* - loescher@lrz.uni-muenchen.de

* Corresponding author

Published: 15 January 2007

Malaria Journal 2007, 6:2 doi:10.1/86/1475-2875-6-2

This article is available from: http://www.malariajournal.com/content/6/1/2

(C) 2007 Schönfeld et al; licensee BioMed Central Ltd.

This is an Open Access article distributed under the terms of the Creative Commons Attribution License (http://creativecommons.org/licenses/by/2.0), which permits unrestricted use, distribution, and reproduction in any medium, provided the original work is properly cited.

\begin{abstract}
Background: In Tanzania, drug-resistant malaria parasites are an increasing public health concern. Because of widespread chloroquine $(\mathrm{CQ})$ resistance Tanzania changed its first line treatment recommendations for uncomplicated malaria from CQ to sulfadoxine-pyrimethamine (SP) in 200I. Loss of SP sensitivity is progressing rapidly. SP resistance is associated with mutations in the dihydrofolate reductase ( $p f d h f r)$ and dihydropteroate synthase ( $p f d h p s)$ genes.
\end{abstract}

Methods: In samples from 86 patients with uncomplicated Plasmodium falciparum malaria from Mbeya and Matema, Mbeya region, south-western Tanzania, the occurrence of mutations was investigated in the pfcrt and pfmdrl genes which are associated with CQ resistance and in pfdhfr and pfdhps, conferring SP resistance, as well in cytb which is linked to resistance to atovaquone.

Results: Pfcrt T76 occurs in 50\% and pfmdrl Y86 in 5I.7\%. Pfdhfr triple mutations coexisting with pfdhps double mutations were detected in $64.3 \%$ of the $P$. falciparum isolates. This quintuple mutation is seen as a possible predictive molecular marker for SP treatment failure. Mutations of the cytb gene were not detected.

Conclusion: These findings of a high prevalence of mutations conferring SP resistance correspond to data of in vivo SP efficacy studies in other regions of Tanzania and underline the recommendation of changing first-line treatment to artemisinin-based combination therapy.

\section{Background}

In Sub-Saharan Africa malaria is a leading cause of morbidity and mortality, especially in children under five years [1]. Despite intensive campaigns, over 10 Million malaria cases occurred in Tanzania in 2003, about 30\% more compared to the previous year [2]. Most of these cases were caused by Plasmodium falciparum. This may be partly due to better surveillance systems, but raising drug 
resistance is the most likely reason for this tremendous increase.

Chloroquine (CQ) was the antimalarial treatment of choice during the second half of the $20^{\text {th }}$ century. But increasing rates of $\mathrm{CQ}$ resistance led Tanzania to change its first line treatment of uncomplicated malaria to sulfadoxine-pyrimethamine (SP) in 2001 [3]. This antifolate combination seemed to be an effective and reasonable alternative, but resistance to SP was rapidly gaining ground, facilitated by the slow elimination from the body. New data show a high level (45\%) of SP treatment failures in Muheza, northeast Tanzania [4]. Other effective drugs, where resistance is as yet not a frequent problem, such as atovaquone-proguanil or mefloquine, are of limited value due to their high current costs [5]. A useful alternative is artemisinin-based combination therapy (ACT), e.g., artemether-lumefantrine which is introduced as the new first line drug in Tanzania in mid 2006. At the moment the availability of ACT is limited; while artemisinin monotherapy formulations and SP are commonly used, especially in the private sector. Some drug shops still sell the relegated CQ.

CQ resistance is associated with an amino acid change from lysine to threonine in codon 76 of the $P$. falciparum chloroquine resistance transporter gene ( $p f c r t$ ) [6], and a mutation from asparagine to tyrosine in codon 86 of the multidrug resistant gene ( $p f m d r$ ) [7-10]. Besides there are indices that $p f m d r 1 \mathrm{~N} 86$ is associated with resistance to lumefantrine that is widely used in combination with artemether [11], and also with decreased sensitivity to artemisinins [12].

SP resistance is associated with mutations in the dihydrofolate reductase ( $p f d h f r)$ and dihydropteroate synthase ( $p f d h p s)$ genes. Pyrimethamine is a selective, competitive inhibitor of dihydrofolate reductase and earlier in the folate pathway sulfa drugs inhibit dihydropteroate synthase $[13,14]$. Several point mutations are connected to antifolate drug resistance. The quintuple mutation (triple pfdhfr: I51, R59, N108 and double pfdhps: G437, E540) is discussed as a relevant molecular marker of SP treatment failure $[15,16]$.

Atovaquone-proguanil is a relatively new antimalarial drug that inhibits mitochondrial electron transport. Point mutations in the $c y t b$ codon 268 are associated with resistance to this combination [17-19].

\section{Methods}

Overall 86 blood samples were collected from patients with clinically diagnosed uncomplicated $P$. falciparum malaria (fever $\geq 38.0^{\circ} \mathrm{C}$, parasitaemia $\geq 2000 / \mu \mathrm{l}$ ) from August to October in 2004 and from June to July in 2005 in Mbeya region of South-western Tanzania. Patients were enrolled at two locations: Matema Health Care Center located in a poor rural area at the shores of Lake Malawi with holoendemic malaria transmission and the Mbeya Referral Hospital, a tertiary hospital at an altitude of 1700 meters that admits complicated cases from surrounding mesoendemic areas or people that have travelled within Tanzania. Written informed consent was obtained from each patient or the parental guide. The study was reviewed and approved by the local IRB at the Mbeya Referral Hospital and the Tanzanian National Ethics Board of the National Institute for Medical Research, Dar es Salaam.

From each patient a finger prick blood sample was taken for thick and thin blood film and another for filter paper blood sample. Giemsa-stained blood films were examined for malaria parasites (per 200 white blood cells) and densities were assessed based on a assumed mean WBC count of $8000 / \mu \mathrm{l}$. DNA extraction from filter paper bloodspots was done using Chelex ${ }^{\circledast}$ (Bio-Rad, Germany) as described elsewhere [20] Nested PCR assays were used to verify the parasite species [21]. The DNA was amplified by nested PCR and digested by the RFLP-method to detect the mutations of $P$. falciparum pfcrt 76, pfmdr1 86, dhfr 16, 51, 59, 108, 164, dhps 436, 437, 540, 581, 613 and $c y t b$ $268[17,22,23]$. Mixed alleles (wild type and mutant) were assessed as mutant. The median age of the 86 patients with $P$. falciparum infection ( 45 female, 41 male) was 21 years (range 8 month to 55 years). All 86 isolates showed $P$. falciparum mono-infection, there was no $P$. vivax, $P$. ovale, or $P$. malariae infection. The geometric mean parasite density was $29992 / \mu l$ (range $3320 / \mu l$ to $127440 / \mu \mathrm{l})$.

\section{Results}

Table 1 displays the prevalence of $p f c r t, p f m d r 1$, pfdhfr, pfdhps and cytb alleles in Mbeya \& Matema. Pfcrt T76 mutation is expressed by $58.8 \%$ in Mbeya and $47.8 \%$ in Matema. $70.6 \%$ of the isolates from Mbeya and $47.1 \%$ from Matema showed the pfmdr1 Y86 mutation. Almost $100 \%$ of both settings exhibited the pfdhfr N108 mutation. Likewise, nearly all samples showed the I51 mutation. All but one displayed the R59 mutation in Mbeya. Amino acid changes from alanine to glycine at codon 437 and from lysine to glutamine at codon 540 of the pfdhps gene were detected in $81 \%$ and $86.9 \%$, respectively. Only one specimen in Matema displayed the G581 variant. No pfdhfr L164 mutation was seen. T108 and V16 variants which are linked with cycloguanil resistance were not present as well. In line with previous reports no evidence for $c y t b$ codon 268 mutations were found in south-western Tanzania [24]. 
Table I: Prevalence of mutations conferring resistance to chloroquine, sulfadoxine-pyrimethamine and atovaquone-proguanil in Plasmodium falciparum isolates from Mbeya \& Matema, southern Tanzania

\begin{tabular}{|c|c|c|c|c|}
\hline Gene & Mutation & $\mathbf{N}$ & Mutation (\%) & Mixed type (\%) \\
\hline Pfcrt & T76 & 86 & $37(43)$ & $6(7)$ \\
\hline Pfmdrl & Y86 & 85 & $38(44.7)$ & $6(7.1)$ \\
\hline \multirow[t]{6}{*}{ Dhfr } & 151 & 86 & $80(93)$ & $0(0)$ \\
\hline & N108 & 86 & $84(97.7)$ & $0(0)$ \\
\hline & TI08 & 86 & $0(0)$ & $0(0)$ \\
\hline & R59 & 86 & $69(80.2)$ & $6(7)$ \\
\hline & VI6 & 86 & $0(0)$ & $0(0)$ \\
\hline & LI 64 & 86 & $0(0)$ & $0(0)$ \\
\hline \multirow[t]{5}{*}{ Dhps } & A436 & 84 & $4(4.8)$ & $3(3.6)$ \\
\hline & G437 & 84 & $66(78.6)$ & $2(2.4)$ \\
\hline & E540 & 84 & 65 (77.4) & $8(9.5)$ \\
\hline & G58I & 81 & $\mathrm{I}(\mathrm{I} .2)$ & $0(0)$ \\
\hline & N6I3 & 81 & $0(0)$ & $0(0)$ \\
\hline Cytb & N268 & 85 & $0(0)$ & $0(0)$ \\
\hline
\end{tabular}

\section{Discussion}

More relevant for predicting treatment failure or emerging resistance are combinations of the point mutations described above (Table 2). In Matema, the rural setting, the Pfdhfr quintuple mutation was more common than in the Mbeya Referral Hospital (67.2\% vs $52.9 \%$ ), while the Pfdhfr triple mutation, suggested to be an early molecular marker for SP resistance in Tanzania [25], was more frequent in Mbeya (79.7\% vs $94.1 \%$ ). Although the predictive value of these markers for SP treatment failure has not been established in the study regions, these results are in line with the high level of treatment failure $(42.3 \%)$ in a multi-site survey in Tanzania [26].

Even so this study investigated a limited number of patients and therefore differences may not reach significance, differences in mutation rates might reflect differences of access to health care between the two locations. While individuals in the rural area receive their malaria treatment, currently SP, almost exclusively through the Matema Health Care Center, patients from Mbeya can choose upon a wide variety of health care facilities and antimalarial drugs. Ongoing usage of CQ may be assumed there.

Although considerably higher resistance rates before 2001 are probable, the still relatively high rate of $p f c r t$ and pfmdr1 mutations is contrary to other reports that have demonstrated a complete regression of pfcrt mutations several years after leaving CQ as first - line antimalarial drug $[27,28]$.

In vivo selection of $p f m d r 186 \mathrm{~N}$ allele by artemether-lumefantrine has been found in Tanzania [11] and pfmdr copy numbers seem to influence susceptibility to lumefantrine and artemisinin [29]. There is no prediction possible due to our results but continuing surveillance would be interesting concerning $p f m d r 1$ polymorphisms.

Table 2: Prevalence of pfcrt, pfmdrl, dhfr and dhps genotype combinations conferring chloroquine and sulfadoxine-pyrimethamine resistance in Mbeya \& Matema, together and each seperated. The risk ratio is the prevalence ratio of the combinations between Mbeya and Matema.

\begin{tabular}{|c|c|c|c|c|c|}
\hline \multicolumn{6}{|c|}{ Grouped alleles } \\
\hline & & Mbeya \& Matema (\%) & Mbeya (\%) & Matema (\%) & Risk ratio \\
\hline Pfcrt+pfmdrl & $T 76+Y 86 * *$ & $29(34.1)$ & $9(52.9)$ & $20(29.4)$ & 0.5556 \\
\hline \multirow[t]{2}{*}{ Dhfr } & $151+N 108 *$ & $80(93)$ & $17(100)$ & $63(91.3)$ & 0.9130 \\
\hline & $|5|+R 59 *$ & $71(82.6)$ & $16(94.1)$ & $55(79.9)$ & 0.8469 \\
\hline Dhfr triple & $15 \mid+R 59+N 108 *$ & $71(82.6)$ & $16(94.1)$ & $55(79.7)$ & 0.8469 \\
\hline Dhps double & $\mathrm{G} 437+\mathrm{E} 540 * * *$ & $68(8 I)$ & $10(58.8)$ & $58(86.6)$ & 1.4716 \\
\hline \multicolumn{2}{|c|}{ Dhfr/dhps quintuple (triple $d h f r+$ double $d h p s$ ) $* * *$} & $54(64.3)$ & $9(52.9)$ & $45(67.2)$ & 1.2687 \\
\hline
\end{tabular}

$* N=86 * * N=85 * * * N=84$ 


\section{Conclusion}

This study confirms the high prevalence of point mutations in the $p f d h f r$ and $p f d h p s$ genes in Tanzania which are associated with SP treatment failure $[25,26]$. The rate of quintuple $p f d h f r / p f d h p s$ mutations in the Mbeya region, south-western Tanzania, is in the upper range of frequencies reported in East Africa. Data from Malawi, Kenya, Tanzania and Ethiopia range from 10 to $78 \%$ [25,30-32]. The absence of $c y t b$ codon 268 supports atovaquone-proguanil as a possible second- or third-line drug for treatment of uncomplicated malaria.

The study data might be used as a basis for surveillance of resistance markers after introduction of ACT and might later indicate the possibility for reintroduction of one of the other drugs.

\section{Authors' contributions}

LM, AK, MH and TL designed the study. MS, IM and LM were responsible for patient recruitment and parasitological examinations. MS, IBM and MS did the PCR assays. $\mathrm{MH}$ did the data processing. MS, AK, IBM, MS, NBR and TL wrote the paper with major contributions of the other authors.

\section{Conflict of interest}

The authors do not have a commercial or other association that might pose a conflict of interest.

\section{Acknowledgements}

We thank MMRP for making their facilities available for this project. We acknowledge the contributions of NIMR, Dr Eleuter Samky, Diretor of Mbeya Referal Hospital and Dr. Donnan Mmbando, Regional Medical Officer for Mbeya Region and Heike Schimanowski, Head of the Matema Health Care Center, for the permission to use their respective facilities and facilitating ethical clearance. Vera Kleinfeldt was responsible for training of all laboratory technicians that participated in the study. This study is part of the thesis work of Mirjam Schönfeld at the Ludwig-Maximilians-University (LMU) Munich, Germany.

\section{References}

I. WHO: World Malaria Report 2005. Geneva 2005.

2. WHO: Global Health Atlas. Geneva 2005.

3. Ministry of Health Tanzania: Malaria Treatment Guidelines. Dar es Salam 2000.

4. Mutabingwa T, Nzila A, Mberu E, Nduati E, Winstanley P, Hills E, Watkins W: Chlorproguanil-dapsone for treatment of drug-resistant falciparum malaria in Tanzania. Lancet 200I, 358: $1218-1223$.

5. Winstanley P: Modern chemotherapeutic options for malaria. Lancet Infect Dis 200I, I:242-250.

6. Djimde A, Doumbo OK, Cortese JF, Kayentao K, Doumbo S, Diourte Y, Dicko A, Su XZ, Nomura T, Fidock DA, Wellems TE, Plowe CV, Coulibaly $D$ : A molecular marker for chloroquine-resistant falciparum malaria. N Engl J Med 200I, 344:257-263.

7. Warhurst DC: Drug resistance in Plasmodium falciparum malaria. Infection 1999, 27(Suppl 2):S55-58.

8. Fidock DA, Nomura T, Talley AK, Cooper RA, Dzekunov SM, Ferdig MT, Ursos LM, Sidhu AB, Naude B, Deitsch KW, Su XZ, Wootton JC, Roepe PD, Wellems TE: Mutations in the $P$. falciparum digestive vacuole transmembrane protein PfCRT and evidence for their role in chloroquine resistance. Mol Cell 2000, 6:86I-87I.
9. Ouellette M: Biochemical and molecular mechanisms of drug resistance in parasites. Trop Med Int Health 200I, 6:874-882.

10. Wellems TE, Plowe CV: Chloroquine-resistant malaria. J Infect Dis 200I, 184:770-776.

II. Sisowath C, Stromberg J, Martensson A, Msellem M, Obondo C, Bjorkman A, Gil JP: In vivo selection of Plasmodium falciparum pfmdrl $86 \mathrm{~N}$ coding alleles by artemether-lumefantrine (Coartem). J Infect Dis 2005, I91(6): 10I4-1017.

12. Duraisingh MT, Jones P, Sambou I, von Seidlein L, Pinder M, Warhurst DC: The tyrosine-86 allele of the pfmdr I gene of Plasmodium falciparum is associated with increased sensitivity to the antimalarials mefloquine and artemisinin. Mol Biochem Parasitol 2000, 108:13-23.

13. Bzik DJ, Li WB, Horii T, Inselburg J: Molecular cloning and sequence analysis of the Plasmodium falciparum dihydrofolate reductase-thymidylate synthase gene. Proc Natl Acad Sci USA 1987, 84:8360-8364.

14. Brooks DR, Wang P, Read M, Watkins WM, Sims PF, Hyde JE: Sequence variation of the hydroxymethyldihydropterin pyrophosphokinase: dihydropteroate synthase gene in lines of the human malaria parasite, Plasmodium falciparum, with differing resistance to sulfadoxine. Eur J Biochem 1994, 224:397-405.

15. Kublin JG, Dzinjalamala FK, Kamwendo DD, Malkin EM, Cortese JF, Martino LM, Mukadam RA, Rogerson SJ, Lescano AG, Molyneux ME, Winstanley PA, Chimpeni P, Taylor TE, Plowe CV: Molecular markers for failure of sulfadoxine-pyrimethamine and chlorproguanil-dapsone treatment of Plasmodium falciparum malaria. J Infect Dis 2002, 185:380-388.

16. Happi CT, Gbotosho GO, Folarin OA, Bolaji OM, Sowunmi A, Kyle DE, Milhous W, Wirth DF, Oduola AM: Association between mutations in Plasmodium falciparum chloroquine resistance transporter and $P$. falciparum multidrug resistance $I$ genes and in vivo amodiaquine resistance in $P$. falciparum malariainfected children in Nigeria. Am J Trop Med Hyg 2006, 75:155-161.

17. Schwobel B, Alifrangis M, Salanti A, Jelinek T: Different mutation patterns of atovaquone resistance to Plasmodium falciparum in vitro and in vivo: rapid detection of codon 268 polymorphisms in the cytochrome $b$ as potential in vivo resistance marker. Malar J 2003, 2:5.

18. Musset L, Bouchaud O, Matheron S, Massias L, Le Bras J: Clinical atovaquone-proguanil resistance of Plasmodium falciparum associated with cytochrome b codon $\mathbf{2 6 8}$ mutations. Microbes Infect 2006 in press.

19. Wichmann O, Muehlberger N, Jelinek T, Alifrangis M, Peyerl-Hoffmann G, Muhlen M, Grobusch MP, Gascon J, Matteelli A, Laferl H, Bisoffi Z, Ehrhardt S, Cuadros J, Hatz C, Gjorup I, McWhinney P, Beran J, da Cunha S, Schulze M, Kollaritsch H, Kern P, Fry G, Richter J, European Network on Surveillance of Imported Infectious Diseases: Screening for mutations related to atovaquone/proguanil resistance in treatment failures and other imported isolates of Plasmodium falciparum in Europe. J Infect Dis 2004, 190:154I-1546.

20. Kain KC, Lanar DE: Determination of genetic variation within Plasmodium falciparum by using enzymatically amplified DNA from filter paper disks impregnated with whole blood. J Clin Microbiol I991, 29: I I7I-I I74.

21. Snounou G, Viriyakosol S, Zhu XP, Jarra W, Pinheiro L, do Rosario $\mathrm{VE}$, Thaithong S, Brown KN: High sensitivity of detection of human malaria parasites by the use of nested polymerase chain reaction. Mol Biochem Parasitol 1993, 61:315-320.

22. Duraisingh MT, Curtis J, Warhurst DC: Plasmodium falciparum : detection of polymorphisms in the dihydrofolate reductase and dihydropteroate synthetase genes by PCR and restriction digestion. Exp Parasitol 1998, 89: I-8.

23. Flueck TP, Jelinek T, Kilian AH, Adagu IS, Kabagambe G, Sonnenburg F, Warhurst DC: Correlation of in vivo-resistance to chloroquine and allelic polymorphisms in Plasmodium falciparum isolates from Uganda. Trop Med Int Health 2000, 5:174- 178.

24. Gil JP, Nogueira F, Stromberg-Norklit J, Lindberg J, Carrolo M, Casimiro C, Lopes D, Arez AP, Cravo PV, Rosario VE: Detection of atovaquone and Malarone resistance conferring mutations in Plasmodium falciparum cytochrome b gene (cytb). Mol Cell Probes 2003, 17:85-89. 
25. Mugittu K, Ndejembi M, Malisa A, Lemnge M, Premji Z, Mwita A, Nkya W, Kataraihya J, Abdulla S, Beck HP, Mshinda H: Therapeutic efficacy of sulfadoxine-pyrimethamine and prevalence of resistance markers in Tanzania prior to revision of malaria treatment policy: Plasmodium falciparum dihydrofolate reductase and dihydropteroate synthase mutations in monitoring in vivo resistance. Am J Trop Med Hyg 2004, 71:696-702.

26. Mugittu K, Abdulla S, Falk N, Masanja H, Felger I, Mshinda H, Beck HP, Genton B: Efficacy of sulfadoxine-pyrimethamine in Tanzania after two years as first-line drug for uncomplicated malaria: assessment protocol and implication for treatment policy strategies. Malar / 2005, 4:55.

27. Kublin JG, Cortese JF, Njunju EM, Mukadam RA, Wirima JJ, Kazembe PN, Djimde AA, Kouriba B, Taylor TE, Plowe CV: Reemergence of chloroquine-sensitive Plasmodium falciparum malaria after cessation of chloroquine use in Malawi. J Infect Dis 2003, I 87:1870-1875.

28. Mita T, Kaneko A, Lum JK, Bwijo B, Takechi M, Zungu IL, Tsukahara T, Tanabe K, Kobayakawa T, Bjorkman A: Recovery of chloroquine sensitivity and low prevalence of the Plasmodium falciparum chloroquine resistance transporter gene mutation K76T following the discontinuance of chloroquine use in Malawi. Am J Trop Med Hyg 2003, 68:4I3-4I5.

29. Sidhu AB, Uhlemann AC, Valderramos SG, Valderramos JC, Krishna $S$, Fidock DA: Decreasing pfmdr I copy number in plasmodium falciparum malaria heightens susceptibility to mefloquine, lumefantrine, halofantrine, quinine, and artemisinin. J Infect Dis 2006, 194:528-535.

30. Bwijo B, Kaneko A, Takechi M, Zungu IL, Moriyama Y, Lum JK, Tsukahara T, Mita T, Takahashi N, Bergqvist Y, Bjorkman A, Kobayakawa $\mathrm{T}$ : High prevalence of quintuple mutant dhps/dhfr genes in Plasmodium falciparum infections seven years after introduction of sulfadoxine and pyrimethamine as first line treatment in Malawi. Acta Trop 2003, 85:363-373.

31. Nzila AM, Mberu EK, Sulo J, Dayo H, Winstanley PA, Sibley CH, Watkins WM: Towards an understanding of the mechanism of pyrimethamine-sulfadoxine resistance in Plasmodium falciparum : genotyping of dihydrofolate reductase and dihydropteroate synthase of Kenyan parasites. Antimicrob Agents Chemother 2000, 44:991-996.

32. Gebru-Woldearegai T, Hailu A, Grobusch MP, Kun JF: Molecular surveillance of mutations in dihydrofolate reductase and dihyropteroate synthase genes of Plasmodium falciparum in Ethiopia. Am J Trop Med Hyg 2005, 73: I I3I-I I 34.

\section{Publish with Bio Med Central and every scientist can read your work free of charge}

"BioMed Central will be the most significant development for disseminating the results of biomedical research in our lifetime. "

Sir Paul Nurse, Cancer Research UK

Your research papers will be:

- available free of charge to the entire biomedical community

- peer reviewed and published immediately upon acceptance

- cited in PubMed and archived on PubMed Central

- yours - you keep the copyright

Submit your manuscript here:

http://www.biomedcentral.com/info/publishing_adv.asp
BioMedcentral 